The final, definitive version of this paper has been published in European Journal of Cardiovascular Prevention and Rehabilitation, vol. 14 no. 1, February 2007 by SAGE Publications Ltd. All rights reserved. (C) SAGE Publications Ltd. 


\title{
Frequency of albuminuria in primary care: a cross-sectional study
}

\author{
Peter Bramlage, David Pittrow, Hendrik Lehnert, Michael Höfler, Wilhelm Kirch, Eberhard \\ Ritz and Hans-Ulrich Wittchen
}

\begin{abstract}
a Institute for Clinical Pharmacology, Medical Faculty, Technical University of Dresden, b Department of Endocrinology and Metabolism, University of Magdeburg, c Warwick University, Medical School, Coventry, UK, d Institute of Clinical Psychology and Psychotherapy, Technical University of Dresden, e Max-Planck Institute of Psychiatry, Munich and f Department of Internal Medicine, Division of Nephrology, Ruperto-Carola-University Heidelberg, Germany
\end{abstract}

Received 23 November 2005 Accepted 5 May 2006

Background We aimed to assess the point prevalence of microalbuminuria (MAU) in a sample of unselected consecutive primary-care attendees, with particular focus on patients with diabetes mellitus (with and without additional concomitant diseases) and those with hypertension.

Design Cross-sectional observational study in a nationwide representative sample of 1912 primarycare practices and a patient population consisting of 39125 primary-care attendees. Diagnoses for diabetes, hypertension and co-morbidities were provided by the treating physician and complemented by blood pressure (BP) measurements and selected lab tests. Screening for microalbuminuria (>20 and $<200 \mathrm{lg} / \mathrm{ml}$ ) was done with a spot urine dipstick test.

Results The clinical diagnosis of nephropathy was assigned to $7.6 \%$ of patients. The point prevalence of MAU was $19.0 \%$ in the total sample; the proportion was $33.6 \%$ in diabetics whereas the diagnosis was assigned to only $7.1 \%$ in the total sample. Amongst diabetic patients with MAU, $92.6 \%$ had BP above the target value of $<130 / 80 \mathrm{mmHg}$. Frequency rates rose with increasing BP (e.g. 20.6\% in diabetic patients with $\mathrm{BP}<120 / 70 \mathrm{mmHg}$, and $36.3 \%$ in diabetic patients with $\mathrm{BP}>140 / 90 \mathrm{mmHg}$ ). Of note, patients with MAU had a higher burden of co-morbidity compared to those without MAU. Conclusions We found a high prevalence of MAU in primary care, particularly in diabetic patients. The frequency of MAU was closely related to the BP level and the degree of co-morbidity. The present study underlines the magnitude of the problem of MAU in primary care, and should serve as a starting point to initiate measures to address this important public health issue.

Keywords: nephropathy, microalbuminuria, prevalence, primary care, risk factors, screening

Sponsorship: This study was supported by an unrestricted educational grant by Sanofi-Aventis Deutschland GmbH, Berlin, Germany.

\section{Introduction}

It is widely acknowledged that in patients with either type 1 or type 2 diabetes, microalbuminuria is a powerful predictor of cardiovascular events and overt diabetic nephropathy [1,2]. It is also a predictor of cardiovascular risk in non-diabetic individuals [3].

As reflected in the recent recommendations of the American Diabetes Association, there is broad consensus that testing for microalbuminuria is an integral part of the management of diabetic patients [4]. The rationale for this recommendation is based on the fact that, first, efficient drug intervention strategies targeted at the renin-aldosterone-angiotensin system 
(RAAS) are available, namely angiotensin-converting enzyme (ACE) inhibitors and angiotensin receptor blockers (ARBs). Second, early treatment provides a window of opportunity as reflected by the much stronger risk reduction in early as compared to late stages of diabetic nephropathy $[5,6]$.

Recent evidence suggests marked deficiencies in the management of diabetic patients by general practitioners in several countries, suggesting that there might be a lack of awareness for the importance of this issue, and consequently a high proportion of diabetic patients remain underdiagnosed and undertreated [6,7]. Several studies in the general population have pointed out that microalbuminuria is a frequent finding, with estimates ranging between 12 and 32\% [8-10]. Unfortunately there is a lack of recent data, describing the prevalence of recognized and unrecognized microalbuminuria among primary-care patients, notably among diabetic patients, who represent a patient group at a particularly high risk.

Therefore we set up a large nationwide primary-care study, named the Hypertension and Diabetes Risk Screening and Awareness Study (HYDRA), screening over 40000 unselected primary-care attendees, to fill this knowledge gap [11]. The aims of the present analysis were: to evaluate the frequency of albuminuria in all primary-care patients and, in particular, in a subset of patients with diabetes mellitus; to examine the frequency of microalbuminuria in the presence of hypertension and/or diabetes; and to assess the association between microalbuminuria and cardiovascular co-morbidities, focusing on micro- and macrovascular complications.

\section{Material and methods}

\section{Study design}

HYDRA is a cross-sectional point prevalence study, based on a two-step observational epidemiological design (for details see http://www.hydra-studie.de) [11]. In step one, a nationwide representative sample of doctors (medical practitioners, generalists, general internists) was recruited on the basis of 1060 regional segments (according to the criteria of the Institute for Medical Statistics (IMS), Frankfurt am Main, Germany), clustered into geographical areas for which primary-care doctor addresses were available. Participating doctors completed a pre-study questionnaire regarding personal and structural characteristics of each practice and to assess self-perceived qualifications and attitudes related to recognition, diagnosis, and care of patients with hypertension, diabetes and other conditions. A total of 1912 primary-care doctors were included (response rate of 79.1\%).

The second step consisted of a target day assessment (two half days) of all consecutive patients attending the doctor's office, irrespective of the reason for contact (target day response rate: $74.2 \%$ ). All attending patients filled out a self-report patient questionnaire (attitudes and health behaviours, awareness of diagnostic status, self-reported treatment, compliance and problems with current medication), followed by a structured doctor's clinical appraisal, including documentation of lab test findings from the charts, blood pressure (BP) measurements, and assessment of microalbuminuria and blood glucose in urine spot samples. The full dataset comprised 45125 patients. Valid information on microalbuminuria, diabetes mellitus and arterial hypertension was available from 39025 patients, which provide the dataset for the present analysis. Analyses checking for representativeness were able to show that this sample was grossly comparable to the full dataset; with patients being slightly younger and having slightly lower rates of concomitant illnesses (data not shown). 


\section{Diagnostic conventions}

Diagnostic findings on arterial hypertension, diabetes mellitus and other diseases in this report are based exclusively on the doctor's clinical appraisal. This included rating of the current presence of hypertension and diabetes using: not present, borderline, mild/ moderate, severe/extreme, and indicating the presence or absence of 22 predefined somatic and mental disorders. Additionally, for all primary target diagnoses of the study (hypertension, diabetes) a wide range of clinical (drug and non-drug treatment, medication, comorbidity, compliance) and course information (age at first diagnosis, treatment, etc.) were assessed, including patient-specific evaluation of the degree to which the doctor believed that diabetes and/or hypertension was controlled. The assessment of patients' actual BP reported in this paper was based on a single measurement of systolic and diastolic BP. It was measured by indirect cuff sphygmomanometry after several minutes of rest in the sitting position, as recommended [12].

The diagnosis of nephropathy was assigned if the doctor indicated that he knew that the patient had diabetic nephropathy (including borderline cases) before enrolling the patient into the study. For the detection of albuminuria in a spot urine sample, the semi-quantitative dipstick Micral-Test II (Boehringer Mannheim, Germany), was used [13], as it has proved useful for screening purposes in a primary-care setting [14]. A positive test result was assigned when the test indicated 20, 50 or $100 \mathrm{mg} / \mathrm{ml}$ albuminuria. Thus, the term albuminuria in the present study stands for a positive one-time positive dipstick test.

Body weight and height information were taken from the patients' questionnaire. Body mass index $(\mathrm{kg} / \mathrm{m} 2)$ was calculated from these self-reported data and classified according to international conventions [15].

\section{Statistical analyses}

Differences in microalbuminuria rates were quantified with odds ratios (ORs) from logistic regressions [16] while adjusted for age group, sex and gender $\mathrm{x}$ age group and calculating robust confidence intervals for observations clustered within primary-care settings [17]. All analyses were conducted using the Stata 8 software package (StataCorp LP, College Station, Texas, USA).

\section{Results}

\section{Sample characteristics}

Table 1 displays key demographic and clinical characteristics of the patients. Typical for a primary-care sample, there was a considerable proportion of elderly patients (aged 65 years and above), a high proportion of overweight and obese patients, and a considerable proportion of patients with diabetes, hypertension or both, respectively (men>women). A total of $7.3 \%$ of patients had nephropathy as diagnosed by the physician, and $15.9 \%$ had diabetes.

\section{Frequency of microalbuminuria}

Table 2 shows that a substantial proportion of all primarycare attendees (total sample: 19.0\%) had microalbuminuria. Rates were almost three times as high as the rates of patients diagnosed as having nephropathy (including borderline) by the physician. Positive findings 
were age-related and a moderate gender difference was found (men>women beyond age 40). Rates of microalbuminuria were particularly high among diabetic patients, especially when these patients had hypertension (overall 35.6\%). High microalbuminuria rates were also found in the presence of microvascular complications (retinopathy, nephropathy, neuropathy, sexual dysfunction and diabetic feet) and macrovascular complications (coronary artery disease, stroke, peripheral arterial disease, etc.). Microalbuminuria was associated not only with a higher number of cardiovascular complications but also with an absolute increase in comorbidity (number of diagnoses, data not shown).

\section{Microalbuminuria in patients with hypertension}

Table 3 displays the prevalence rates of microalbuminuria according to BP categories in the total sample, as well as in patients without diabetes versus with diabetes. In nondiabetic patients with a BP below 140/90mmHg the prevalence rates were comparable (15.6, 13.3 and $14.1 \%$ respectively) and increased beyond $140 / 90 \mathrm{mmHg}$ to $19.8 \%$. In contrast to this, an increase in BP was closely related to an increase in microalbuminuria in diabetic patients over the whole range of BP categories, to a high of $36.3 \%$ in patients with BP $>140 / 90 \mathrm{mmHg}$. In the presence of macrovascular complications (coronary artery disease, stroke, peripheral arterial disease, etc.), microalbuminuria rates in diabetics were further increased throughout all BP categories (maximum: 41.3\%).

\section{Microalbuminuria in patients with co-morbidities}

Table 4 shows the association of microalbuminuria with 15 frequent diseases, in the total sample as well as divided into patients with and without diabetes. In almost all conditions, the rates of microalbuminuria were increased compared to those patients without the respective disease. The diseases associated with the highest increase in risk for microalbuminuria (as indicated by high ORs) in the total sample, but also in diabetic patients, were (in declining order) diabetic feet, retinopathy, neuropathy, peripheral arterial disease, left ventricular hypertrophy and sexual dysfunction.

Patients with microalbuminuria had a higher co-morbidity burden, expressed as categories of the number of diseases, and there was a monotonic relationship between the degree of comorbidity and the prevalence of microalbuminuria. The respective risk was substantially increased compared to patients without microalbuminuria, as indicated by the ORs; for example, the odds of having two to three additional diseases was increased in the former group (no additional diseases) by about 60\% (OR 1.6), and of having four to five additional diseases by about 120\% (OR 2.2). Similar risk increases were seen in both diabetic and nondiabetic patients with microalbuminuria (detailed data not shown).

\section{Discussion}

There are three key findings in our study. First, the frequency of albuminuria in primary care is high: every fifth patient in our study had a positive spot test finding. Secondly, in both diabetic and hypertensive patients prevalence rates were higher than in non-diabetic, normotensive patients. The presence of high BP levels $(<140 / 90 \mathrm{mmHg})$ in the total cohort, particularly in diabetic patients, as well as the presence of microvascular or macrovascular complications, was associated with high rates of microalbuminuria. Thirdly, patients with microalbuminuria had a substantially higher burden of co-morbidity compared to those without microalbuminuria. 


\section{Strengths and limitations}

Before discussing these key findings, the strength and limitations of this paper should be considered. The strengths of the study are: that it concerns a large nationwide, representative sample of family doctors' offices and of patients; and that the study design allowed us to obtain information on diagnostic interventions, cardiovascular disease management and comorbidity, not only from the physician, but also from the patient. This allowed the assessment of information deficits both on the patients' and physicians' side. According to Lum [18] the dipstick test as used in this study 'is inexpensive, easy and rapid to perform' and effective at all prevalence rates. Sensitivity values of the Micral II test compared with 24-h nephelometry were $93 \%$ and specificity $94 \%$, in a random sample of primary-care attendees [13]. Using the albumin/creatinine ratio would have provided increased sensitivity, but this measurement was impractical for logistic reasons. Yet, random urine specimens are more variable than 24-h or morning urine samples, presumably reflecting diurnal variation of BP and glomerular filtration rate (GFR), but receiver-operating characteristics indicate acceptable specificity and sensitivity [19]. An important limitation is that, for logistic reasons, the number of items assessed had to be limited; unfortunately data on smoking status could not be obtained. Likewise, albuminuria could only be assessed on a single occasion. This does not allow estimation of how many patients would be positive or negative on a second testing. Derived from data obtained by the Third National Health and Nutrition Examination Survey

(NHANES III) [20], one could estimate that at least 65\% of the negatively tested patients will test positive on a subsequent occasion.

\section{Point prevalence of a positive dipstick test}

It is noteworthy that our estimated prevalence of $19 \%$ is generally in good accordance with findings previously reported in various other epidemiological studies, none of which, however, was performed in primary care, which is a high-risk population compared with the community. The prevalence of microalbuminuria was reported to be $23 \%$ in France [21]. In Canada, the prevalence was $32 \%$ in diabetic and $15 \%$ in non-diabetic individuals [22]. In a recent Australian study [23], overt proteinuria was found in $0.8 \%$ of a random general population sample under 44 years and $7 \%$ over 65 years. It was increased by a factor of four in diabetic individuals. In NHANES III the prevalence of microalbuminuria in diabetics was $29 \%$ (about $8 \%$ in non-diabetics). On the other hand, a previous German study in general practitioner offices [24] found microalbuminuria in $4 \%$ of normotensive, $10 \%$ of hypertensive and $17 \%$ of diabetic individuals, respectively. Overt proteinuria was present in $8 \%$ of diabetics under 60 years of age and in 13\% of diabetics aged over 60 years. In 85421 adult inhabitants of Groningen, microalbuminuria was reported in 16\% of diabetic patients [25].

It is of note that the usual cut-off for microalbuminuria, which was also applied in our study, is to be considered arbitrary in the light of current research. Diabetic patients with baseline albumin excretion rate values of 20-30 mg/24 h had an accelerated decline in GFR, and an elevated risk for cardiovascular events [26]. According to current data from the communitybased Framingham cohort with middle-aged, non-hypertensive, non-diabetic individuals, low levels of urinary albumin excretion well below the current microalbuminuria threshold predicted the development of cardiovascular disease [27]. The data have been confirmed by a study of Romundstad et al. [28], which found a similar relationship between microalbuminuria and cardiovascular risk. 
The major determinant of microalbuminuria in diabetic $[29,30]$ as well as in non-diabetic individuals is hypertension $[24,25]$. There is also sound evidence that microalbuminuria is related to sub-diabetic glycaemia [31] as well as to inflammatory markers and endothelial dysfunction [32] as a potential reflection of atherosclerosis [33]. Overall, increasing levels of albuminuria are an independent indicator of cardiovascular risk factors and cardiovascular morbidity [25,34], more so in men than in women [35].

\section{Co-morbidities}

Earlier cross-sectional studies suggest that microalbuminuria, a marker of glomerular hyperfiltration and endothelial dysfunction, may be a feature of hypertension and a marker of target-organ damage [24]. Urinary albumin excretion predicts BP progression in nondiabetic, non-hypertensive individuals incrementally better than established risk factors, and at levels well below the conventional threshold for microalbuminuria [36]. Our study highlights the size of the problem in primary care: the albuminuria prevalence in the total sample, even in patients below the hypertension thresholds (tight control $<120 / 70 \mathrm{mmHg}$, conventional r140/ $90 \mathrm{mmHg}$ ), was in the order of 15\% (in diabetics 21- 29\%), which shows the proportion of patients at increased risk for hypertension, organ damage and cardiovascular events. Our analysis of patients with various concomitant diseases sheds light on the fact that a series of other conditions is associated with a high prevalence of microalbuminuria, and thus with the risks described above. In this context, it was disappointing that achieved BP values (the most important modifiable risk factor) were far off the recommended targets for high-risk populations [4]. This observation is in line with previous observations of non-compliance with best-practice guidelines in type 2 diabetics, even by self-selected physicians [37].

\section{Perspective: treatment options}

The single microalbuminuria measurements in our study would have to be confirmed by another test finding (rule: two out of three must be positive) according to American Diabetes Association (ADA) recommendations, before treatment is initiated [4]. But if the diagnosis of microalbuminuria is established, aggressive lowering of elevated BP will be mandatory in diabetics, along with general measures (protein restriction, glycaemic control) [4]. Antihypertensive drugs with proven renoprotective efficacy are the first choice. The Irbesartan Microalbuminuria in Type-2-Diabetes Trial (IRMA-2) with irbesartan [5] has shown that the progression of nephropathy can be slowed under ARB therapy. Even in patients with manifest nephropathy, this effect translates into decreased disease progression [6].

In conclusion, our analysis shows the magnitude of the problem in primary care: a large proportion of patients has microalbuminuria and therefore is at increased risk. From a public health standpoint, microalbuminuria screening in type 2 diabetics is cost effective [38] and standard management programmes in screened patients have been shown to cause major cost saving [39]. Consequently, we recommend standard screening of primary-care patients to offer patients at risk the option of early modification of risk factors. For patients with microalbuminuria or overt renal dysfunction, an aggressive RAAS-based approach to hypertension management, combining potent BP control with proven renoprotection, holds the key for therapy targeted towards long-term cardiovascular protection. This study should serve as the basis to address the highly prevalent problem of microalbuminuria in primary care. 


\section{References}

1 Mogensen CE, Keane WF, Bennett PH, Jerums G, Parving HH, Passa P, et al. Prevention of diabetic renal disease with special reference to microalbuminuria. Lancet 1995; 346:1080-1084.

2 Sarnak MJ, Levey AS, Schoolwerth AC, Coresh J, Culleton B, Hamm LL, et al. Kidney disease as a risk factor for development of cardiovascular disease: a statement from the American Heart Association Councils on Kidney in Cardiovascular Disease, High Blood Pressure Research, Clinical Cardiology, and Epidemiology and Prevention. Circulation 2003; 108:2154-2169.

3 Savage S, Estacio RO, Jeffers B, Schrier RW. Urinary albumin excretion as a predictor of diabetic retinopathy, neuropathy, and cardiovascular disease in NIDDM. Diabetes Care 1996; 19:1243-1248. 4 Molitch ME, DeFronzo RA, Franz MJ, Keane WF, Mogensen CE, Parving HH, et al. Nephropathy in diabetes. Diabetes Care 2004; 27(suppl 1): S79-83.

5 Parving HH, Lehnert H, Brochner-Mortensen J, Gomis R, Andersen S, Arner P. The effect of irbesartan on the development of diabetic nephropathy in patients with type 2 diabetes. $\mathrm{N}$ Engl J Med 2001; 345:870-878.

6 Lewis EJ, Hunsicker LG, Clarke WR, Berl T, Pohl MA, Lewis JB, et al. Renoprotective effect of the angiotensin-receptor antagonist irbesartan in patients with nephropathy due to type 2 diabetes. $\mathrm{N}$ Engl J Med 2001; 345:851-860.

7 Gaede P, Vedel P, Larsen N, Jensen GV, Parving HH, Pedersen O. Multifactorial intervention and cardiovascular disease in patients with type 2 diabetes. N Engl J Med 2003; 348:383-393.

8 Adler AI, Stevens RJ, Manley SE, Bilous RW, Cull CA, Holman RR. Development and progression of nephropathy in type 2 diabetes: The United Kingdom Prospective Diabetes Study (UKPDS 64). Kidney Int 2003; 63:225-232.

9 Jones CA, Francis ME, Eberhardt MS, Chavers B, Coresh J, Engelgau M, et al. Microalbuminuria in the US population: third National Health and Nutrition Examination Survey. Am J Kidney Dis 2002; 39:445-459.

10 Pontremoli R, Leoncini G, Ravera M, Viazzi F, Vettoretti S, Ratto E, et al. Microalbuminuria, cardiovascular, and renal risk in primary hypertension. J Am Soc Nephrol 2002; 13(suppl 3):S169172.

11 Sharma AM, Wittchen HU, Kirch W, Pittrow D, Ritz E, Goke B, et al. High prevalence and poor control of hypertension in primary care: cross-sectional study. J Hypertens 2004; 22:479-486.

12 WHO. World Health Organization-International Society of Hypertension Guidelines for the Management of Hypertension. J Hypertens 1999; 17:151-183.

13 Gerber LM, Johnston K, Alderman MH. Assessment of a new dipstick test in screening for microalbuminuria in patients with hypertension. Am J Hypertens 1998; 11:1321-1327.

14 Piehlmeier W, Renner R, Schramm W, Kimmerling T, Garbe S, Proetzsch R, et al. Screening of diabetic patients for microalbuminuria in primary care-The PROSIT-Project. Proteinuria Screening and Intervention. Exp Clin Endocrinol Diabetes 1999; 107:244-251.

15 WHO Obesity: preventing and managing the global epidemic. Report of a WHO consultation. World Health Organ Tech Rep Ser No. 894. Geneva: WHO; 2000.

16 McCullagh P, Nelder JA. Generalized linear models. 2nd ed. London: Chapman \& Hall; 1989.

17 Royall RM. Model robust confidence intervals using maximum likelihood estimators. Int Stat Rev 1986; 54:221-226.

18 Lum G. How effective are screening tests for microalbuminuria in random urine specimens? Ann Clin Lab Sci 2000; 30:406-411.

19 Zelmanovitz T, Gross JL, Oliveira JR, Paggi A, Tatsch M, Azevedo MJ. The receiver operating characteristics curve in the evaluation of a random urine specimen as a screening test for diabetic nephropathy. Diabetes Care 1997; 20:516-519.

20 Coresh J, Astor BC, Greene T, Eknoyan G, Levey AS. Prevalence of chronic kidney disease and decreased kidney function in the adult US population: Third National Health and Nutrition Examination Survey. Am J Kidney Dis 2003; 41:1-12.

21 Passa P, Chatellier G. The DIAB-HYCAR Study. Diabetologia 1996; 39:1662-1667.

22 Gerstein HC, Mann JF, Yi Q, Zinman B, Dinneen SF, Hoogwerf B, et al. Albuminuria and risk of cardiovascular events, death, and heart failure in diabetic and nondiabetic individuals. JAMA 2001; 286:421-426. 
23 Chadban SJ, Briganti EM, Kerr PG, Dunstan DW,Welborn TA, Zimmet PZ, et al. Prevalence of kidney damage in Australian adults: The AusDiab kidney study. J Am Soc Nephrol 2003; 14:S131138.

24 Horner D, Fliser D, Klimm HP, Ritz E. Albuminuria in normotensive and hypertensive individuals attending offices of general practitioners. J Hypertens 1996; 14:655-660.

25 Hillege HL, Janssen WM, Bak AA, Diercks GF, Grobbee DE, Crijns HJ, et al. Microalbuminuria is common, also in a nondiabetic, nonhypertensive population, and an independent indicator of cardiovascular risk factors and cardiovascular morbidity. J Intern Med 2001; 249:519-526.

26 Rachmani R, Levi Z, Lidar M, Slavachevski I, Half-Onn E, Ravid M. Considerations about the threshold value of microalbuminuria in patients with diabetes mellitus: lessons from an 8-year followup study of 599 patients. Diabetes Res Clin Pract 2000; 49:187-194.

27 Arnlov J, Evans JC, Meigs JB, Wang TJ, Fox CS, Levy D, et al. Low-grade albuminuria and incidence of cardiovascular disease events in nonhypertensive and nondiabetic individuals: The Framingham Heart Study. Circulation 2005; 112:969-975.

28 Romundstad S, Holmen J, Hallan H, Kvenild K, Kruger O, Midthjell K. Microalbuminuria, cardiovascular disease and risk factors in a nondiabetic/nonhypertensive population. The NordTrondelag Health Study (HUNT, 1995-97), Norway. J Intern Med 2002; 252:164-172.

29 Vestbo E, Damsgaard EM, Froland A, Mogensen CE. Urinary albumin excretion in a population based cohort. Diabet Med 1995; 12:488-493.

30 Haneda M, Kikkawa R, Togawa M, Koya D, Kajiwara N, Uzu T, et al. High blood pressure is a risk factor for the development of microalbuminuria in Japanese subjects with non-insulin-dependent diabetes mellitus. J Diabetes Complications 1992; 6:181-185.

31 Meigs JB, D’Agostino RB Sr, Nathan DM, Rifai N,Wilson PW. Longitudinal association of glycemia and microalbuminuria: the Framingham Offspring Study. Diabetes Care 2002; 25:977-983. 32 Stehouwer CD, Gall MA, Twisk JW, Knudsen E, Emeis JJ, Parving HH. Increased urinary albumin excretion, endothelial dysfunction, and chronic low-grade inflammation in type 2 diabetes:

progressive, interrelated, and independently associated with risk of death. Diabetes 2002; 51:11571165.

33 Festa A, D’Agostino R, Howard G, Mykkanen L, Tracy RP, Haffner SM. Inflammation and microalbuminuria in nondiabetic and type 2 diabetic subjects: The Insulin Resistance Atherosclerosis Study. Kidney Int 2000; 58:1703-1710.

34 Hillege HL, Fidler V, Diercks GF, van Gilst WH, de Zeeuw D, van Veldhuisen DJ, et al. Urinary albumin excretion predicts cardiovascular and noncardiovascular mortality in general population. Circulation 2002; 106:1777-1782.

35 Verhave JC, Hillege HL, Burgerhof JG, Navis G, de Zeeuw D, de Jong PE. Cardiovascular risk factors are differently associated with urinary albumin excretion in men and women. J Am Soc Nephrol 2003; 14:1330-1335.

36 Wang TJ, Evans JC, Meigs JB, Rifai N, Fox CS, D’Agostino RB, et al. Low-Grade albuminuria and the risks of hypertension and blood pressure progression. Circulation 2005; 111:1370-1376. 37 Mottur-Pilson C, Snow V, Bartlett K. Physician explanations for failing to comply with 'best practices'. Eff Clin Pract 2001; 4:207-213.

38 Lepore G, Maglio ML, Nosari I, Dodesini AR, Trevisan R. Cost-effectiveness of two screening programs for microalbuminuria in type 2 diabetes. Diabetes Care 2002; 25:2103-2104; author reply 2104.

39 Gozzoli V, Palmer AJ, Brandt A, Weiss C, Piehlmeier W, Landgraf R, et al. Increased clinical and economic advantages using PROSIT (proteinuria screening and intervention) in type 2 diabetic patients [in German]. Dtsch Med Wochenschr 2000; 125:1154-1159. 